\title{
Perforated gastrointestinal stromal tumor in the small intestine: A rare case of Torricelli-Bernoulli sign
}

\author{
TAKAYUKI TAJIMA ${ }^{1}$, TAKAYUKI NISHI $^{1}$, MIFUJI TOMIOKU $^{1}$, TAKASHI OGIMI $^{1}$, \\ LIN FUNG CHAN $^{1}$, TAKASHI OKAZAKI ${ }^{2}$, KAZUNORI MYOUJIN ${ }^{3}$ and HIDEO SHIMADA ${ }^{1}$ \\ ${ }^{1}$ Department of Surgery, Tokai University Oiso Hospital, Kanagawa 259-0189; ${ }^{2}$ Department of Radiology, Tokai University \\ Hospital, Kanagawa 259-1193; ${ }^{3}$ Department of Radiology, Tokai University Oiso Hospital, Kanagawa 259-0189, Japan
}

Received February 22, 2018; Accepted July 11, 2018

DOI: $10.3892 / \mathrm{mco} .2018 .1699$

\begin{abstract}
The Torricelli-Bernoulli sign is a computed tomography (CT) finding that occurs when ulceration/necrosis of a submucosal gastrointestinal tumor releases a stream of air bubbles into the intestinal lumen. A 75-year-old man developed acute abdominal pain at night and presented to a local doctor. Acute abdomen was diagnosed and he was referred to the Emergency Department at Tokai University Oiso Hospital. On CT scans, disseminated intestinal tumor-like lesions were seen in the right lower abdomen. The Torricelli-Bernoulli sign and free intraabdominal gas were observed, so perforation of an intestinal tumor was diagnosed and emergency surgery was performed. At operation, there was scanty opaque ascites in the right lower abdomen and an ileal tumor associated with nodules that suggested peritoneal dissemination. Partial resection of the ileum was performed and peritoneal lavage was conducted. The patient was discharged on postoperative day 11 . Histopathological examination revealed a high risk gastrointestinal stromal tumor. The abdominal nodules were metastases, indicating that the tumor was Stage IV. The patient is currently on treatment with an oral tyrosine kinase inhibitor (imatinib).
\end{abstract}

\section{Introduction}

The Torricelli-Bernoulli sign (T-B sign) (1) is observed by computed tomography (CT) when an ulcerated/necrotic submucosal gastrointestinal tumor releases air bubbles into the intestinal lumen (2). Gastrointestinal stromal tumors (GISTs)

Correspondence to: Dr Takayuki Tajima, Department of Surgery, Tokai University Oiso Hospital, 21-1 Gakkyo, Naka-gun, Kanagawa 259-0189, Japan

E-mail: takayukitajima1970@yahoo.co.jp

Abbreviations: GIST, gastrointestinal stromal tumor; T-B sign, Torricelli-Bernoulli sign; CT, computed tomography

Key words: Torricelli-Bernoulli sign, small intestine, gastrointestinal stromal tumor originate from Cajal cells (intestinal pacemaker cells) in the interstitial tissues of the gastrointestinal wall. While more than $90 \%$ of GISTs express the receptor tyrosine kinase c-kit on the cell surface, some tumors are negative for c-kit (3). Immunohistochemistry is needed to confirm the diagnosis of GIST (4). Approximately $70 \%$ of these tumors occur in the stomach, followed by $20-30 \%$ in the small intestine and $10 \%$ elsewhere in the intestines $(5,6)$. There are no characteristic symptoms/signs of GIST, but it commonly causes fever, abdominal pain, abdominal discomfort, intestinal bleeding, or intestinal obstruction (7-11). We encountered a patient who had perforated intestinal GIST associated with the T-B sign. We performed a PubMed search for previous reports about perforated intestinal GIST used the keywords 'perforated GIST', 'free air', and 'small intestine', and we identified 6 articles (12-17). One of these articles reported a mass with an air/fluid level, but did not mention the T-B sign (17). We also conducted a search including the term 'T-B sign', but could not identify any additional literature. Accordingly, this rare case of perforated GIST with the T-B sign is reported here.

\section{Case report}

Written informed consent was obtained from the patient and his family for publication of this case report and the accompanying images. The patient was a 75-year-old man with a history of appendectomy, gastric ulcer, and old pulmonary tuberculosis. He was being treated for diabetes at a local clinic. In early March 2017, he developed acute abdominal pain and was referred to Tokai University Oiso hospital. At the initial examination, his height was $170 \mathrm{~cm}$, weight was $65 \mathrm{~kg}$, pulse rate was 115/min (sinus rhythm), blood pressure was $115 / 85 \mathrm{mmHg}$, and body temperature was $36.4^{\circ} \mathrm{C}$. Conjunctival pallor suggesting anemia was observed, but there was no jaundice. Rebound tenderness was detected, particularly in the lower right abdomen. Due to exacerbation of pain, acute abdomen was diagnosed. Laboratory tests revealed a white blood cell (WBC) count of 19000/ $\mu 1$ and elevation of C-reactive protein (CRP) to $17.95 \mathrm{mg} / \mathrm{dl}$. Hb was $8.8 \mathrm{~g} / \mathrm{dl}$, indicating anemia. Blood glucose was $191 \mathrm{mg} / \mathrm{dl}$ and $\mathrm{HbAlc}$ was $8.3 \%$. CT scans revealed an intestinal mass lesion with so called T-B sign which showed mass with an air/ fluid level and free gas in the lower right abdomen, findings corresponding to 
the T-B sign, as well as another intestinal tumor with adjacent nodules that were considered to represent peritoneal dissemination (Fig. 1). Based on these findings, a perforated intestinal tumor with dissemination was diagnosed. Emergency surgery was conducted via a midline lower abdominal incision. A small amount of purulent opaque ascites was observed in the lower right abdomen. There was an ileal tumor located about $30 \mathrm{~cm}$ from the ileocecal junction showing adhesion to the greater omentum and peritoneal dissemination was observed in the surrounding area. After partial resection of the small intestine, part of the greater omentum was also resected and peritoneal sampling was conducted. The postoperative clinical course was uncomplicated and the patient was discharged at 11 days after surgery. Examination of the resected specimen revealed an ileal tumor with extramural growth and a diameter of $55 \mathrm{~mm}$. Whitish exudate was present on the serosal surface of the tumor and there was a deep necrotic ulcer at the luminal surface (Fig. 2A). Multiple paraffin blocks were prepared and processed in a routine manner. Then sections were cut and were stained with hematoxylin and eosin or for immunohistochemistry. Histopathological examination revealed a submucosal tumor composed of proliferating spindle-shaped cells with a mucoid interstitium. The tumor cells were epithelioid-like and had strongly eosinophilic cytoplasm, with 5 mitotic figures per 50 high power fields. The serosal surface of the tumor was coated with fibrin and inflammatory or necrotic exudate. These findings were consistent with tumor perforation (Fig. 2B and C). The intraperitoneal masses had similar cellular architecture to the primary tumor and were diagnosed as peritoneal dissemination. Immunohistochemistry was positive for CD34, c-kit, DOG1, and Ki-67 (MIB-1) in 15\% of the tumor cells, while SMA, S100, and desmin were negative. The tumor was high risk according to the Miettinenn classification/modified-Fletcher classification. According to the Union for International Cancer Control (UICC)/TNM classification (7th edition, 2009), the diagnosis was pT3, pN1, M0, Stage IV.

CT scanning and abdominal ultrasound were conducted at one month postoperatively, with ultrasound detecting 3 hepatic metastases $<10 \mathrm{~mm}$ in diameter that were not confirmed by CT. Oral administration of the tyrosine kinase inhibitor imatinib resulted in disappearance of the peritoneal lesions, while cystic degeneration of the metastatic liver tumors was seen on both CT and abdominal ultrasound. Treatment is ongoing at 9 months after surgery and there has been no evidence of recurrence.

\section{Discussion}

The Torricelli-Bernoulli (T-B) sign (1) is based on Torricelli's law proposed by Evangelista Torricelli (18) and the Bernoulli principle proposed by Daiel Bernoulli (19). This sign occurs when internal necrosis of a submucosal tumor (leiomyosarcoma or GIST) is associated with ulceration into the intestinal lumen, releasing a stream of air bubbles that can be visualized by diagnostic imaging (2). It is rare for an intestinal GIST $\leq 5 \mathrm{~cm}$ in diameter to develop ulceration, and it has been reported that the T-B sign generally occurs in patients with tumors $\geq 6 \mathrm{~cm}$ in size (20). Our patient's tumor was only $5.5 \mathrm{~cm}$ in diameter, but the T-B sign was still observed after it underwent necrosis.

While CT is most frequently used for preoperative imaging in patients with intestinal tumors (21), MRI is also useful for

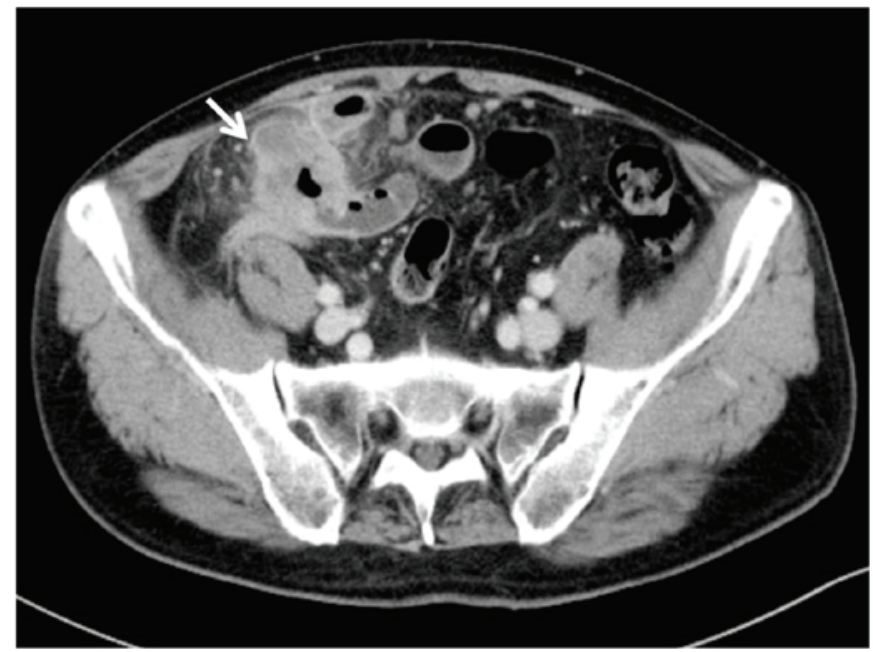

Figure 1. Abdominal contrast CT scan. There is an intestinal tumor in the right lower abdomen, with the T-B sign and air inside the tumor (arrow).
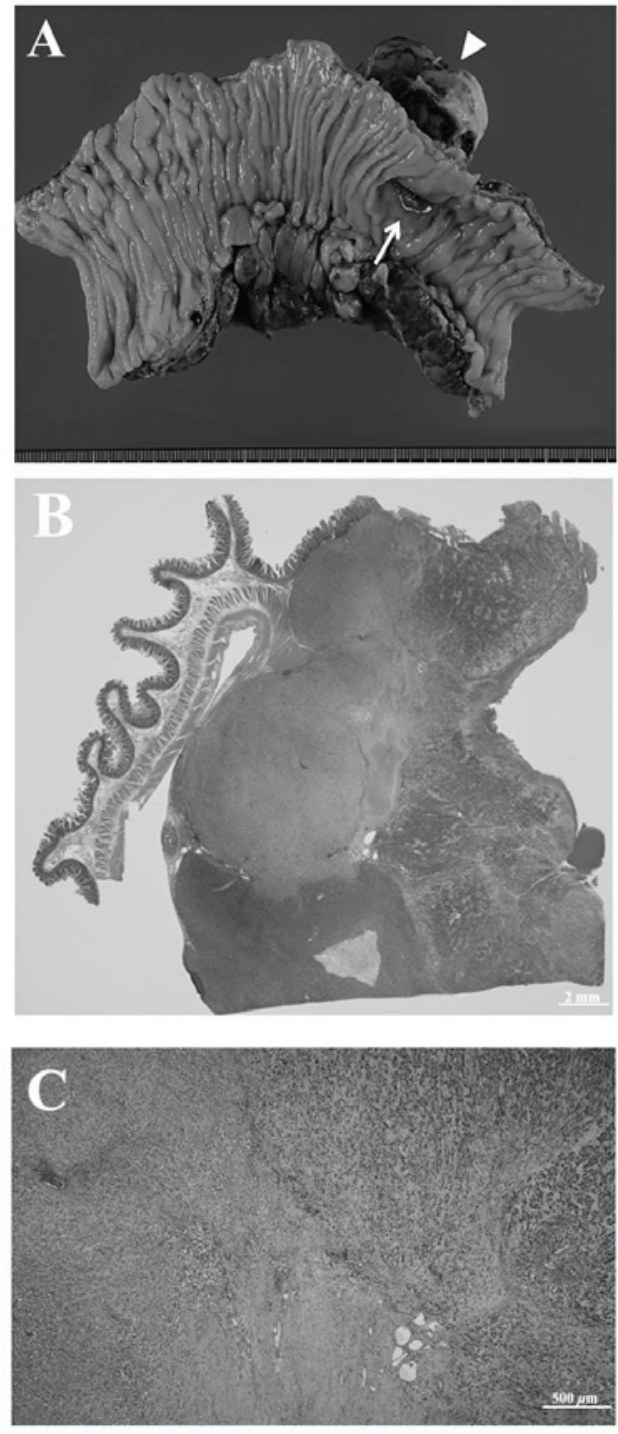

Figure 2. Resected specimen. (A) Macroscopic appearance, an ulcer (arrow) is observed in the small intestine at the site of a tumor with extramural growth (arrowhead). (B) Thin section, the submucosal tumor shows necrosis and ulceration with necrotic exudate on the serosal surface, indicating perforation. (C) Histopathological findings, the tumor architecture is diverse. GIST was diagnosed by immunohistochemistry. 
the detection of rectal GIST and liver metastasis (22). To confirm the diagnosis of GIST, immunohistochemistry should be performed on a tumor specimen to detect c-kit (a receptor tyrosine kinase protein encoded by kit) and CD34, as well as using the monoclonal antibody DOG1 to stain chloride ion channel protein, with the positive rate being $\geq 80-90 \%$ for these markers $(3,23)$. However, our patient had acute abdomen and required emergency surgery, so biopsy of the lesion could not be performed for diagnosis. Our patient's tumor showed positive immunostaining for c-kit, CD34, and DOG1, confirming the diagnosis of intestinal GIST (22).

GIST is considered to originate from Cajal cells in the interstitial tissue of the gastrointestinal wall, which are pacemaker cells that regulate intestinal motility (4). Approximately $25-35 \%$ of GISTs arise in the small intestine, while the most frequent site is the stomach, accounting for $60-70 \%$. The colon, rectum, and esophagus are uncommon sites for GIST ( $<10 \%$ each) (8). Small GISTs $\leq 2 \mathrm{~cm}$ in diameter are usually asymptomatic and are generally found incidentally by imaging examinations or during surgery for other diseases. Most of these small tumors are benign (8) There are no characteristic signs of intestinal GIST (22), but patients frequently develop fever, abdominal pain, and abdominal discomfort. Other symptoms include intestinal bleeding, fatigue related to anemia, and respiratory distress (8-11). At diagnosis, $\sim 50 \%$ of patients already have liver metastasis and peritoneal dissemination $(8,24,25)$. The first-line treatment for GIST is surgery, if the tumor is resectable $(26,27)$. Our patient presented with tumor perforation and acute abdomen, so emergency surgery with small bowel resection was required. However, peritoneal dissemination was observed during surgery (mainly in the lower right abdomen) and liver metastases were detected by postoperative imaging.

Administration of imatinib, a first-generation tyrosine kinase inhibitor was initiated after surgery (28). Follow-up imaging after initiation of imatinib therapy revealed cystic degeneration of liver metastases and disappearance of the peritoneal lesions, suggesting that this treatment was effective. In patients with severe adverse reactions to imatinib or those who show an insufficient response, second-generation tyrosine kinase inhibitors like sunitinib or regorafenib have been reported to be effective (29-31).

Preoperative diagnosis of intestinal GIST is quite challenging and immunohistochemical staining is required for confirmation. However, detection of the T-B sign on CT may be a useful diagnostic clue in patients with a perforated submucosal tumor.

\section{Acknowledgements}

Not applicable.

\section{Funding}

No funding was received.

\section{Availability of data and materials}

The datasets obtained and/or analyzed during the current study are available from the corresponding author on reasonable request.

\section{Authors' contributions}

TT and TN conceived and designed this case report. TT wrote the initial draft of the report. MT, TO and LFC acquired the data in the surgical field. TO and KM acquired the data in the diagnostic imaging. HS supervised the study and critically reviewed the manuscript. All authors have read and approved the final version of the manuscript.

\section{Ethics approval and consent to participate}

Written informed consent for surgery was obtained from the patient.

\section{Patient consent for publication}

Written informed consent for publication of the present report was obtained from the patient.

\section{Competing interests}

The authors declare that they have no conflicts of interest.

\section{References}

1. Fortman BJ: Torricelli-Bernoulli sign in an ulcerating gastric leiomyosarcoma. AJR Am J Roentgenol 173: 199-200, 1999.

2. Sureka B, Bansal K and Arora A: Torricelli-Bernoulli Sign in gastrointestinal stromal tumor. AJR Am J Roentgenol 205: W468-W468, 2015.

3. Hirota S, Isozaki K, Moriyama Y, Hashimoto K, Nishida T, Ishiguro S, Kawano K, Hanada M, Kurata A, Takeda M, et al: Gain-of-function mutations of c-kit in human gastrointestinal stromal tumors. Science 279: 577-580, 1998.

4. Kindblom LG, Remotti HE, Aldenborg F and Meis-Kindblom JM: Gastrointestinal pacemaker cell tumor (GIPACT): Gastrointestinal stromal tumors show phenotypic characteristics of the interstitial cells of Cajal. Am J Pathol 152: 1259-1269, 1998.

5. Miettinen M, Sarlomo-Rikala M and Lasota J: Gastrointestinal stromal tumors: Recent advances in understanding of their biology. Hum Pathol 30: 1213-1220, 1999.

6. Graadt van Roggen JF, van Velthuysen MLF and Hogendoorn PCW: The histopathological differential diagnosis of gastrointestinal stromal tumours. J Clin Pathol 54: 96-102, 2001.

7. Ludwig DJ and Traverso LW: Gut stromal tumors and their clinical behavior. Am J Surg 173: 390-394, 1997.

8. Connolly EM, Gaffney E and Reynolds JV: Gastrointestinal stromal tumours. Br J Surg 90: 1178-1186, 2003.

9. Miettinen M and Lasota J: Gastrointestinal stromal tumors-definition, clinical, histological, immunohistochemical, and molecular genetic features and differential diagnosis. Virchows Arch 438: 1-12, 2001.

10. Ueyama T, Guo KJ, Hashimoto H, Daimaru Y and Enjoji M: A clinicopathologic and immunohistochemical study of gastrointestinal stromal tumors. Cancer 69: 947-955, 1992.

11. Baheti AD, Shinagare AB, O'Neill AC, Krajewski KM, Hornick JL, George S, Ramaiya NH and Tirumani SH: MDCT and clinicopathological features of small bowel gastrointestinal stromal tumours in 102 patients: a single institute experience. $\mathrm{Br}$ J Radiol 88: 20150085, 2015.

12. Efremidou EI, Liratzopoulos N, Papageorgiou MS, Romanidis K, Manolas KJ and Minopoulos GJ: Perforated GIST of the small intestine as a rare cause of acute abdomen: Surgical treatment and adjuvant therapy. Case report. J Gastrointestin Liver Dis 15: 297-299, 2006.

13. Misawa S, Takeda M, Sakamoto H, Kirii Y, Ota H and Takagi H: Spontaneous rupture of a giant gastrointestinal stromal tumor of the jejunum: A case report and literature review. World J Surg Oncol 12: 153, 2014. 
14. Shoji M, Yoshimitsu Y, Maeda T, Sakuma H, Nakai M and Ueda H: Perforated gastrointestinal stromal tumor (GIST) in a true jejunal diverticulum in adulthood: Report of a case. Surg Today 44: 2180-2186, 2014.

15. Khuri S, Gilshtein H, Darawshy AA, Bahouth H and Kluger Y: Primary small bowel GIST presenting as a life-threatening emergency: A report of two cases. Case Rep Surg 2017: 1814254, 2017.

16. Alessiani M, Gianola M, Rossi S, Perfetti V, Serra P, Zelaschi D, Magnani E and Cobianchi L: Peritonitis secondary to spontaneous perforation of a primary gastrointestinal stromal tumour of the small intestine: A case report and a literature review. Int J Surg Case Rep 6C: 58-62, 2015.

17. Sato K, Tazawa H, Fujisaki S, Fukuhara S, Imaoka K, Hirata Y, Takahashi M, Fukuda S, Kuga Y, Nishida T, et al: Acute diffuse peritonitis due to spontaneous rupture of a primary gastrointestinal stromal tumor of the jejunum: A case report. Int J Surg Case Rep 39: 288-292, 2017.

18. Driver R: Toricelli's law: An ideal example of an elementary ODE. Am Math Mon 105: 453-455, 1998

19. Stedman TL: Stedman's Medical Dictionary. 25th Edition. Williams \& Wkjins, Baltimore, p182, 1990.

20. Nishida T, Kumano S, Sugiura T, Ikushima H, Nishikawa K, Ito $\mathrm{T}$ and Matsuda $\mathrm{H}$ : Multidetector $\mathrm{CT}$ of high-risk patients with occult gastrointestinal stromal tumors. AJR Am J Roentgenol 180: 185-189, 2003.

21. Amano M, Okuda T, Amano Y, Tajiri T and Kumazaki T: Magnetic resonance imaging of gastrointestinal stromal tumor in the abdomen and pelvis. Clin Imaging 30: 127-131, 2006.

22. Grover S, Ashley SW and Raut CP: Small intestine gastrointestinal stromal tumors. Curr Opin Gastroenterol 28: 113-123, 2012.

23. West RB, Corless CL, Chen X, Rubin BP, Subramanian S, Montgomery K, Zhu S, Ball CA, Nielsen TO, Patel R, et al: The novel marker, DOG1, is expressed ubiquitously in gastrointestinal stromal tumors irrespective of KIT or PDGFRA mutation status. Am J Pathol 165: 107-113, 2004.

24. DeMatteo RP, Lewis JJ, Leung D, Mudan SS, Woodruff JM and Brennan MF: Two hundred gastrointestinal stromal tumors: Recurrence patterns and prognostic factors for survival. Ann Surg 231: 51-58, 2000.
25. Emory TS, Sobin LH, Lukes L, Lee DH and O'Leary TJ: Prognosis of gastrointestinal smooth-muscle (stromal) tumors: Dependence on anatomic site. Am J Surg Pathol 23: 82-87, 1999.

26. Demetri GD, von Mehren M, Antonescu CR, Dematteo RP, Ganjoo KN, Maki RG, Pisters PWT, Raut CP, Riedel RF, Schuetze S, Sundar HM, Trent JC and Wayne JD: NCCN Task Force report: update on the management of patients with gastrointestinal stromal tumors. J Natl Compr Canc Netw 8(suppl 2); S1-S41: quiz S42-S44: 2010.

27. ESMO/European Sarcoma Network Working Group: Gastrointestinal stromal tumors: ESMO Clinical Practice Guidelines for diagnosis, treatment and follow-up. Ann Oncol 23: vii49-vii55, 2012.

28. Demetri GD, von Mehren M, Blanke CD, Van den Abbeele AD, Eisenberg B, Roberts PJ, Heinrich MC, Tuveson DA, Singer S, Janicek M, et al: Efficacy and safety of imatinib mesylate in advanced gastrointestinal stromal tumors. N Engl J Med 347: 472-480, 2002

29. Demetri GD, van Oosterom AT, Garrett CR, Blackstein ME, Shah MH, Verweij J, McArthur G, Judson IR, Heinrich MC, Morgan JA, et al: Efficacy and safety of sunitinib in patients with advanced gastrointestinal stromal tumour after failure of imatinib: A randomised controlled trial. Lancet 368: 1329-1338, 2006.

30. Wilhelm SM, Dumas J, Adnane L, Lynch M, Carter CA, Schütz G, Thierauch KH and Zopf D: Regorafenib (BAY 73-4506): A new oral multikinase inhibitor of angiogenic, stromal and oncogenic receptor tyrosine kinases with potent preclinical antitumor activity. Int J Cancer 129: 245-255, 2011.

31. Kajiura S, Hosokawa A, Nanjyo S, Nakada N, Ando T and Sugiyama T: A case of a gastrointestinal stromal tumor of the rectum effectively treated with continuously-administered regorafenib after failure of imatinib and sunitinib. Nihon Shokakibyo Gakkai Zasshi 113: 655-661, 2016 (In Japanese). 